\title{
SISTEM INFORMASI PENDAFTARAN KONSULTASI KLIEN BERBASIS WEB PADA KLINIK IPWL BNN
}

\author{
Zainal Arifin ${ }^{*}$, Ragil Wijianto Adhi ${ }^{2}$ \\ ${ }^{1,2}$ Sistem Informasi, Universitas Nusa Mandiri \\ email:11207003@nusamandiri.ac.id*
}

\begin{abstract}
Abstrak: Proses pendaftaran konsultasi klien di klinik IPWL BNN yang masih dilakukan secara manual, tidak efisien dan efektif terutama bagi calon klien yang berdomisili jauh dari kantor BNN karena membutuhkan waktu dan biaya yang lebih banyak. Selain itu juga beresiko seperti hilangnya formulir pendaftaran yang memuat data pribadi klien. Dengan memanfaatkan teknologi internet, adanya sebuah website pendaftaran konsultasi klien yang dapat diakses secara online dimana dan kapan saja, diharapkan dapat mempermudah proses pendaftaran konsultasi klien. Website ini dibuat menggunakan metode waterfall, yang pengembangan sistemnya menggunakan bahasa pemrograman PHP dan basis data MySQL. Dari hasil dari penelitian yang dilakukan, dapat diambil kesimpulan bahwa Sistem Informasi Pendaftaran Konsultasi Klien Berbasis Web merupakan solusi agar proses pendaftaran konsultasi klien di Klinik IPWL BNN lebih efektif dan efisien.
\end{abstract}

Kata Kunci : Sistem, Informasi, Pendaftaran Konsultasi Klien, Website

Abstract: The process of client consulting registration at BNN's IPWL Clinic which is still done manually, is not efficient and effective, especially for prospective client who live far from the BNN office because it requires more time and money. In addition, there are also risks such as the loss of registration forms that contain client's personal data. By utilizing internet technology, the existence of a client consulting registration website that can be accessed online anywhere and anytime, is expected to facilitate the process of client consulting registration. This website is created using the waterfall method, the development of the system using the PHP programming language and MySQL database. From the results of the research conducted, it can be concluded that the Client Consulting Registration Information System is a solution so that the process of registration new client at BNN's IPWL Clinic is more effective and efficient.

Keywords : System, Information, Client Consulting Registration, Website

\section{PENDAHULUAN}

Badan Narkotika Nasional (BNN) adalah sebuah Lembaga Pemerintah Non Kementerian Indonesia yang melaksanakan tugas pemerintahan dibidang pencegahan, pemberantasan penyalahgunaan dan peredaran gelap narkoba (P4GN). Rehabilitasi narkoba merupakan bagian dari kegiatan pemberantasan penyalahgunaan narkoba yang bertujuan untuk memulihkan pecandu agar terbebas dari penyalaghunaan narkoba. Untuk menjalankan kegiatan rehabilitasi tersebut, BNN mengalami kendala dalam proses penjangkauan dan pendampingan pecandu atau korban penyalahguna narkoba.

Dalam pelaksanaan kegiatan penjangkauan pecandu atau korban penyalahguna narkoba, kendala yang ditemukan antara lain adanya stigma negatif masyarakat yang beranggapan bahwa penyalahgunaan narkoba adalah sebuah aib keluarga, sehingga sangat sedikit sekali keluarga yang melaporkan kerabat atau anggota keluarganya untuk mendaftarkan diri guna mengikuti layanan rehabilitasi secara sukarela. Stigma tersebut berdampak pada munculnya ketakukan seseorang atau kerabat penyalahguna narkoba untuk datang ke klinik Institusi Penerima Wajib Lapor (IPWL) BNN [1].

Berdasarkan hasil observasi yang dilakukan di klinik IPWL BNN, proses pendaftaran konsultasi untuk kerabat atau seseorang penyalahguna yang biasa disebut klien masih dilakukan secara manual, sehingga dinilai kurang efektif dan efisien [2]. Selain itu data pasien akan sulit dicari dan kemungkinan besar akan mudah rusak sehingga digitalisasi dirasa sangat diperlukan agar data dapat dengan cepat diproses, tidak mudah rusak dan terdokumentasi dengan baik agar mudah dicari [3].

Oleh karena itu perlu dibuatkan sebuah sistem informasi pendaftaran konsultasi klien untuk memudahkan dalam mendaftarkan diri mengikuti rehabilitasi tanpa harus datang ke klinik IPWL BNN terlebih dahulu yang mana dinilai sangat membuangbuang waktu dan uang transportasi klien sehingga dinilai sangat tidak efektif dan efisien.

\section{TINJAUAN PUSTAKA \\ Sistem Informasi}

Menurut Wilkinson dalam [4] Sistem informasi adalah Sumber daya seperti manusia atau komputer yang dikoordinasikan oleh sebuah kerangka kerja untuk mengolah masukan (input) menjadi keluaran (informasi), guna mencapai sasaran dan tujuan perusahaan. Sedangkan menurut Hall dalam [4] Sistem informasi dapat dijelaskan sebagai sebuah rangkaian prosedur formal dimana data dapat dikelompokkan, diproses menjadi sebuah informasi, dan didistribusikan kepada pengguna. 


\section{Basis Data}

Basis data didefinisikan sebagai media untuk menyimpan data agar dapat dengan mudah dan cepat diakses jika dibutuhkan [5]. Basis data berfungsi untuk menampung atau menyimpan kumpulan data ke dalam sebuah tabel agar bisa lebih mudah diakses, dimana masing-masing data yang ada pada tabel tersebut memiliki relasi satu sama lainnya.

\section{Entity Relationship Diagram (ERD)}

ERD adalah pemodelan awal basis data yang paling banyak digunakan. Diagram Entity Relationship adalah gambaran sebuah diagram yang menjelaskan hubungan antar entity di dalam sebuah database [6]. ERD terdiri dari beberapa objek yang digambarkan dengan menggunakan simbol-simbol grafis tertentu yang saling berhubungan satu sama lainnya. Dengan mendefinisikan sebuah entitas beserta atribut yang menunjukkan hubungan di antarnya, ERD menggambarkan struktur logis dari sebuah rangkaian basis data.

\section{Website}

Web atau istilah lengkapnya World Wide Web (WWW) sering disebut juga website atau situs. Website dapat diartikan sebagai kumpulan halaman yang berisi informasi data digital baik berupa teks, gambar, animasi, suara dan video atau gabungan daris semuanya yang disediakan melalui jalur koneksi internet [7]. Perkembangan website saat ini semakin maju dan banyak digunakan baik oleh intitusi swasta maupun institusi pemerintahan.

\section{Unified Modelling Laguage (UML)}

Menurut Sukamto dan Shalahuddin dalam [8], UML adalah standar bahasa yang paling banyak dan umum digunakan sebagai sarana perancangan sistem dalam mendefinisikan requirement, membuat analisis dan desain, serta menggambarkan arsitektur dalam pemrograman berorientasi objek. UML dapat diklasifikasikan ke dalam beberapa diagram, yaitu:

\section{Use Case Diagram}

Memberikan memberikan narasi hubungan antara usecase, aktor dan sistem. untuk memberikan gambaran interaksi antara pengguna sistem dengan sistem itu sendiri.

2. Activity Diagram

Menggambarkan langkah-langkah atau prosedur dari suatu proses bisnis dari sistem yang kita buat.

3. Class Diagram

Menggambarkan struktur sistem seperti kelas sistem (class), atribut (property), operasi (method) dan hubungan antar objek.

4. Component Diagram

Menggambarkan komponen terhubung melalui user inteface yang dibutuhkan dalam pemodelan fisik pada sistem object-oriented dan berfokus pada komponen sistem yang sering digunakan.

\section{Deployment Diagram}

Menggambarkan bagian dari perangkat lunak mana yang berjalan pada perangkat keras yang mana.

\section{METODE}

\section{Teknik Pengumpulan Data}

A. Observasi

Penulis mengamati kebutuhan data dan informasi yang ada pada klinik IPWL BNN. Data yang sudah dikumpulkan akan disajikan dalam bentuk website agar user mendapatkan informasi yang dibutuhkan di dalam web.

\section{B. Wawancara}

Melakukan tanya jawab kepada petugas klinik IPWL BNN untuk mengetahui informasi yang dibutuhkan pada proses perancangan sistem informasi.

\section{Studi Pustaka}

Penulis melakukan studi kepustakaan dari bukubuku, jurnal-jurnal, dan bahan penulisan lainnya guna pengumpulan data, teori-teori pendukung, referensi data yang dapat dijadikan sebagai objek penelitian dan penyusunan skripsi.

\section{Model Pengembangan Sistem}

Model pengembangan sistem yang penulis gunakan adalah metode pengembangan sistem dengan model air terjun (waterfall). Menurut Rosa A.S \& M. Salahuddin dalam bukunya menjelaskan bahwa Model SDLC air terjun (waterfall) sering juga di sebut sebagai model sekuensial linier (sequential linear) atau alur hidup klasik (clasic life cycle). Model air terjun menyediakan pendekatan alur hidup perangkat lunak secara sekuensial atau terurut dimulai dari analisis, desain, pengodean, pengujian, dan tahap pendukung (support) [5]

A. Analisa Kebutuhan Sistem

Pada tahap awal, penulis memberikan batasanbatasan kebutuhan agar pengembangan sistem mempunyai tujuan yang jelas, perangkat lunak dapat mudah dipahami dan sesuai dengan yang diharapkan. Informasi dapat diperoleh melalui observasi, wawancara dan diskusi. Kemudian informasi yang sudah diterima dianalisis kembali dan dirancang menjadi sebuah sistem.

\section{B. Desain}

Pada tahap ini, penulis akan merancang bentuk antarmuka (interface) dari sistem informasi yang sesuai dengan kebutuhan penggunaan. Dengan mendesain tampilan antarmuka diharapkan dapat membuat sistem informasi lebih mudah digunakan oleh pengguna (user). Proses bisnis digambarkan menggunakan metode pemodelan Unified Modelling Language (UML), dan untuk perancangan database menggunakan Entity Relationship Diagram (ERD) dan Logical Record Structure (LRS). 
LRS adalah representasi dari struktur record-record pada tabel-tabel yang terbentuk dari hasil antar himpunan entitas pada diagram E-R [9]. LRS pada sistem informasi pendaftaran konsultasi klien sebagai berikut dibawah ini.

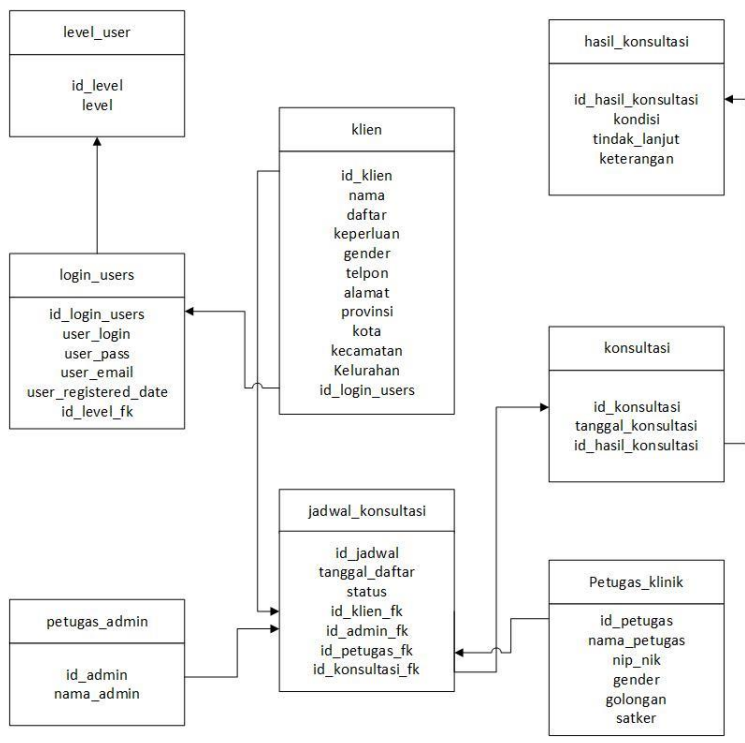

Gambar 1.

LRS Sistem informasi Pendaftaran Konsultasi Klien

\section{Code Generation}

Hasil perancangan user interface, proses bisnis dan desain kemudian diterjemahkan melalui proses coding. Metode pemrograman yang digunakan adalah pemrograman berorientasi objek. Menggunakan editor Microsoft Visual Studio Code, bahasa pemrograman yaitu PHP dan database yang digunakan adalah MySQL.

\section{Testing}

Testing dilakukan untuk menentukan apakah program atau sistem yang dibuat telah memenuhi hasil yang diharapkan. Salah satu metode testing menggunakan metode black box testing.

\section{E. Support}

Pada tahap ini sistem informasi sudah selesai dibuat, untuk menjaga sistem informasi yang dijalankan tetap berjalan dengan baik, maka perlu dilakukan pemeliharaan untuk perubahan atau pengembangan pada sistem informasi sesuai kebutuhan pengguna.

\section{HASIL DAN PEMBAHASAN}

Klinik IPWL BNN memberikan layanan konsultasi bagi pecandu Narkotika yang sudah cukup umur atau keluarganya, dan/atau orang tua atau wali dari pecandu narkotika yang belum cukup umur kepada IPWL untuk mendapatkan pengobatan dan/atau perawatan melalui rehabilitasi medis.

Proses pendaftaran klien dimulai dari calon klien datang ke Klinik IPWL BNN. Calon klien menerima formulir pendaftaran dari petugas administrasi untuk diisi. Calon klien harus melengkapi formulir pendaftaran tersebut sebelum diserahkan kembali kepada petugas administrasi. Formulir pendaftaran yang diserahkan akan diperiksa oleh petugas administrasi mengenai kelengkapannya.

Setelah data dan kelengkapan persyaratan dianggap cukup, maka petugas administrasi akan mengatur jadwal pelaksanaan konsultasi dan menentukan petugas klinik yang menanganinya. Petugas administrasi akan mengkonfirmasikan jadwal yang sudah ditetapkan tersebut kepada calon klien.

Calon klien bertemu dengan petugas klinik untuk melakukan konsultasi. Petugas klinik mencatat hasil konsultasi tersebut dan menyerahkan kepada petugas administrasi untuk disusun dalam sebuah laporan. Petugas administrasi kemudian membuat laporan berupa hasil konsultasi klien untuk

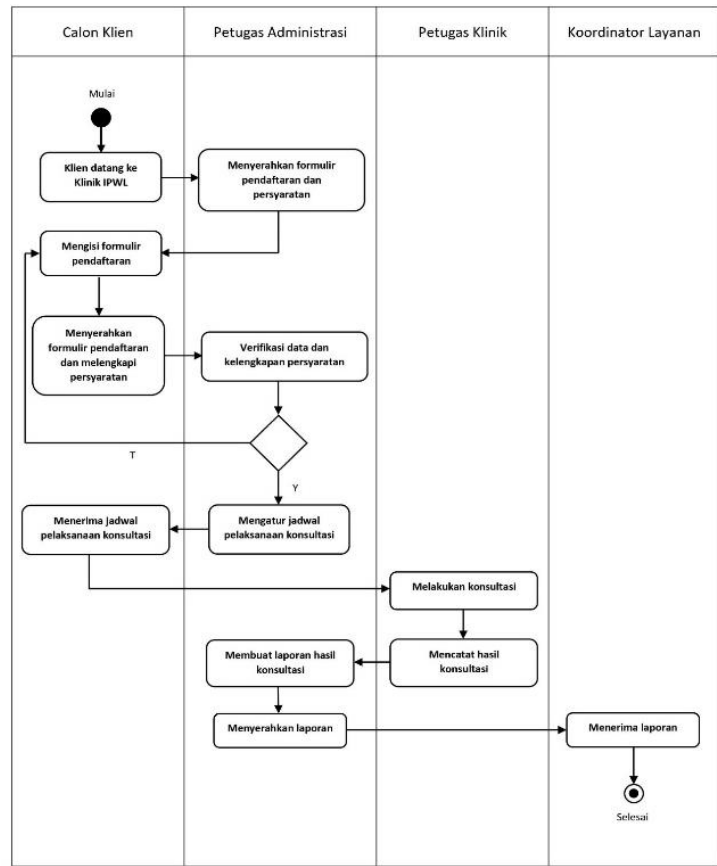

diserahkan kepada koordinator layanan.

Gambar 2.

Activity Diagram Prosedur Pendaftaran Konsultasi

\section{Proses Bisnis Sistem Usulan}

A. Tahapan Analisis

Berikut ini merupakan spesifikasi kebutuhan (system requirement):

Halaman Klien:

B.1. Calon klien dapat mengisi formulir pendaftaran B.2. Calon klien dapat melihat jadwal konsultasi B.3. Calon klien dapat melihat hasil konsultasi. Halaman Petugas Klinik:

C.1. Petugas klinik dapat melihat jadwal penerimaan konsultasi.

C.2. Petugas klinik dapat menuliskan rekomendasi hasil konsultasi.

Halaman Petugas Administrasi:

D.1. Petugas administrasi dapat melihat data-data pendaftar konsultasi. 
D.2. Petugas administrasi dapat menentukan jadwal dan petugas pelaksanaan konsultasi

D.3. Petugas administrasi dapat melihat dan mengunduh rekap data laporan hasil konsultasi klien dengan petugas klinik.

B. Usecase Diagram

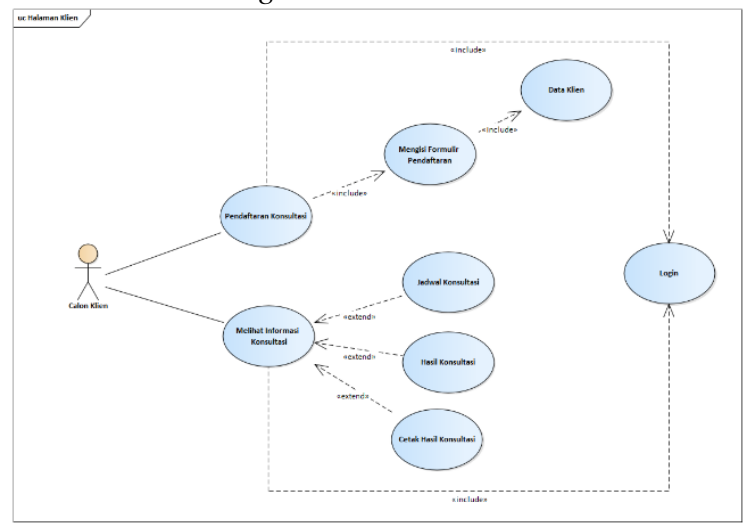

Gambar 3. Use Case Diagram Halaman Klien

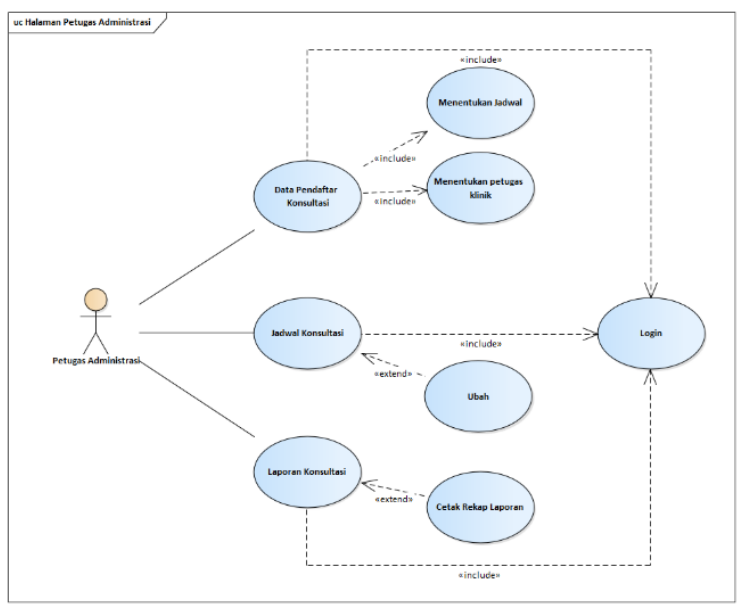

Gambar 4. Use Case Diagram Halaman Petugas Administrasi

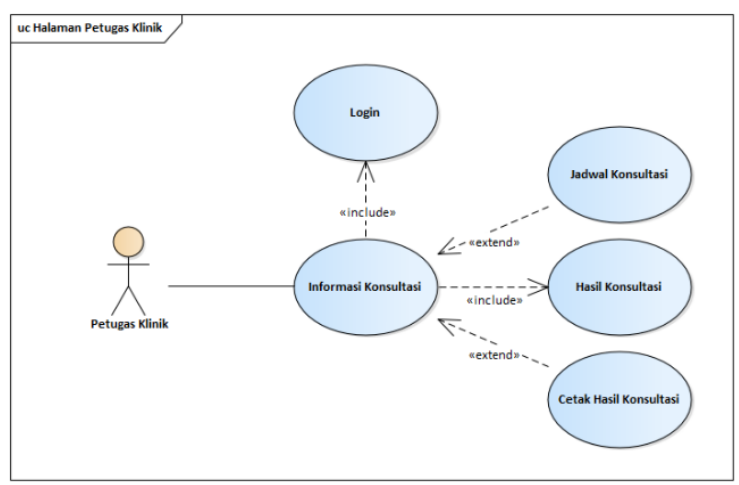

Gambar 5. Use Case Diagram Halaman Petugas Klinik

Pada beberapa gambar di atas menggambarkan hubungan tiap-tiap pengguna (user) dengan sistem dalam sistem informasi pendaftaran konsultasi klien.

\section{Activity Diagram}

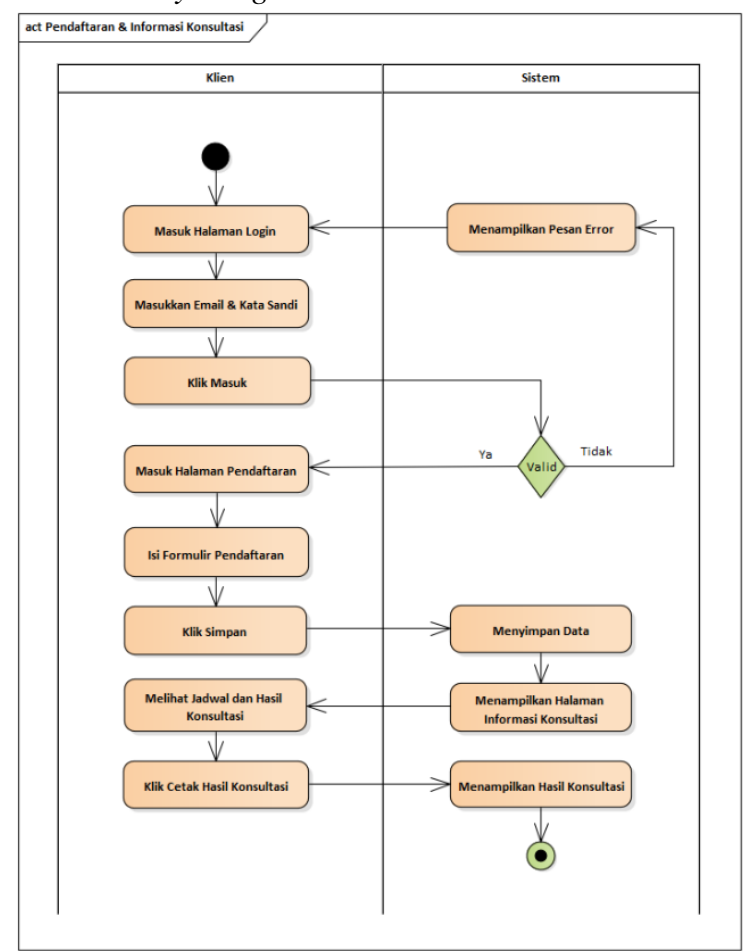

Gambar 6. Activity Diagram Proses Pendaftaran dan Informasi Konsultasi

Pada gambar 6 digambarkan proses-proses yang terjadi pada sebuah sistem pendaftaran konsultasi klien.

D. Software Architecture

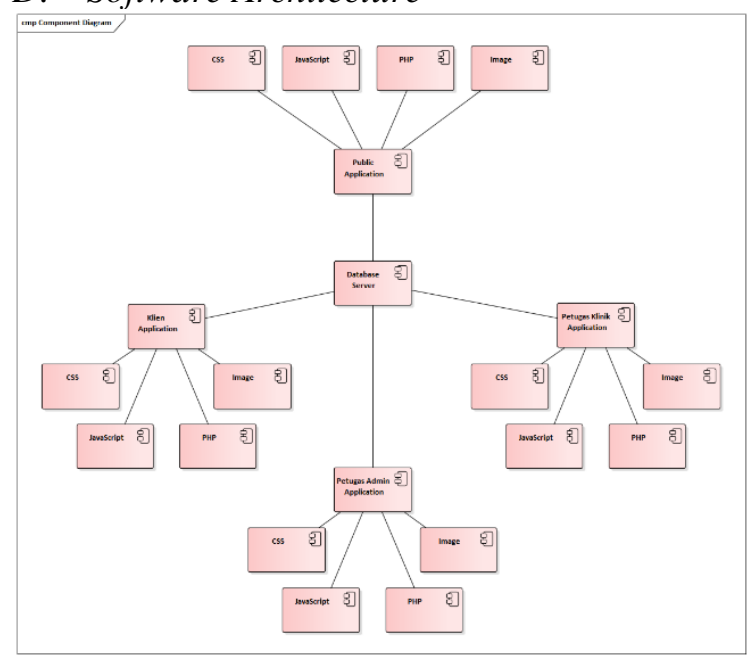

Gambar 7. Component Diagram Pendaftaran Konsultasi Klien

Pada gambar 7 digambarkan hubungan antar komponen perangkat lunak yang digunakan dalam sistem informasi pendaftaran konsultasi klien. 


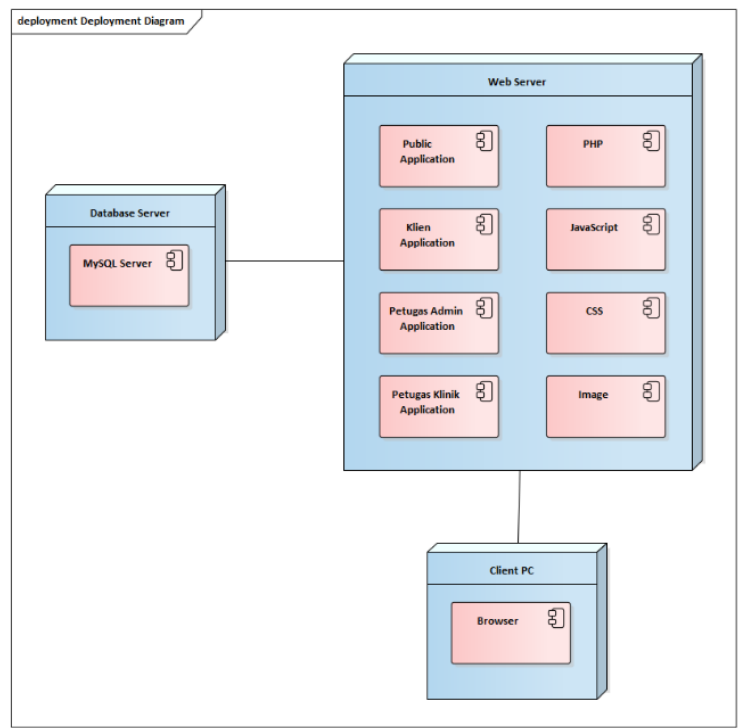

Gambar 8. Deployment Diagram Pendaftaran Konsultasi Klien

Hubungan antara perangkat lunak dan perangkat keras pada sistem informasi pendaftaran konsultasi klien yang dibangun dapat digambarkan dengan deployment diagram seperti pada gambar 8 .

\section{Desain}

Tiap-tiap user yang terlibat pada sistem informasi pendaftaran konsultasi klien seperti klien, petugas administrasi, petugas klinik serta super admin dapat mengakses halaman akunnya dengan alamat email yang terdaftar dan kata sandi yang telah ditetapkan masing-masing user.

Dari tiap-tiap user tersebut memiliki wewenang yang berbeda berdasarkan tugas dan fungsinya dalam pelaksanaan program rehabilitasi di klinik IPWL BNN RI.

\section{Layanan Konsultasi Calon Klien Rehabilitasi}

\section{Silahkan Masuk}

Alamat Email

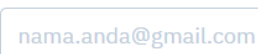

Kata Sandi

\section{Enter your password}

\section{Masuk}

Belum punya akun? Silahkan dafta
Sebagai contoh pada user klien, dapat melakukan login ke halaman klien seperti pada gambar 9 setelah sebelumnya melakukan pendaftaran akun terlebih dulu.

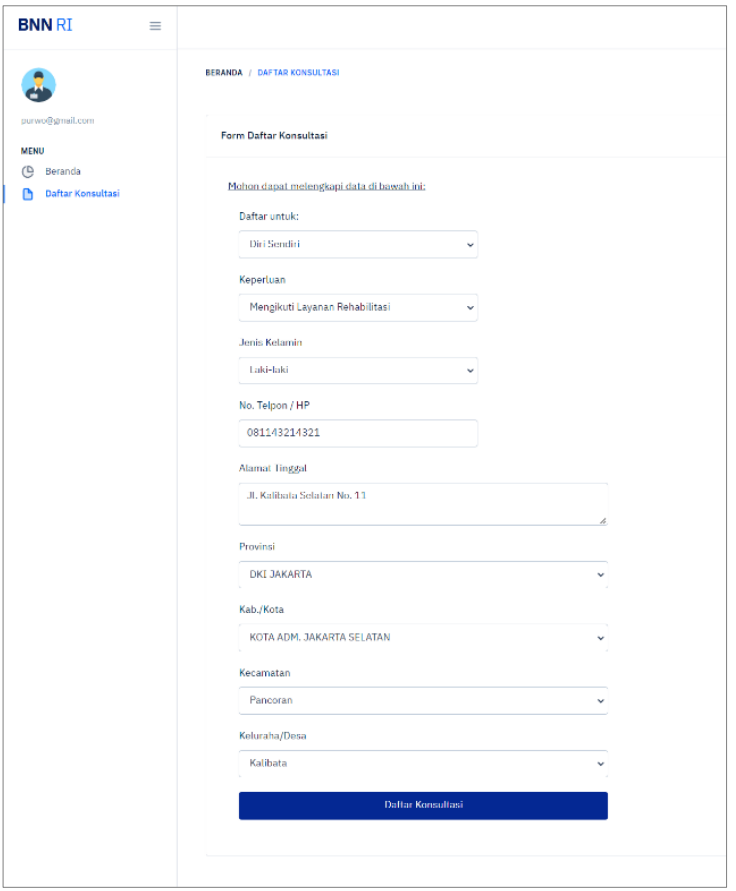

Gambar 10. Tampilan Form Pendaftaran Konsultasi Klien

Seperti yang tertera pada gambar 10, klien dapat melakukan pendaftaran konsultasi dengan melengkapi form pendaftaran konsultasi yang telah tersedia.

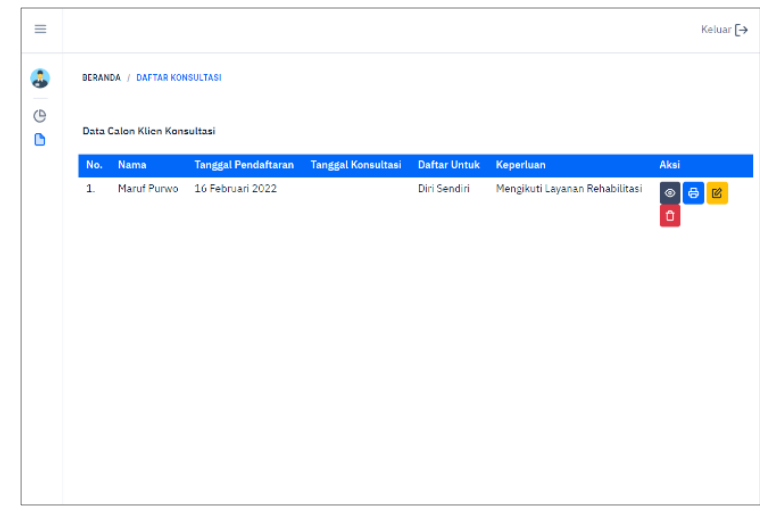

Gambar 11. Tampilan Halaman Konsultasi Klien

Setelah klien melakukan pendaftaran konsultasi, akan diarahkan ke halaman konsultasi klien pada gambar 11. Pada halaman ini nantinya klien akan melihat jadwal dan hasil dari pelaksanaan konsultasi. 


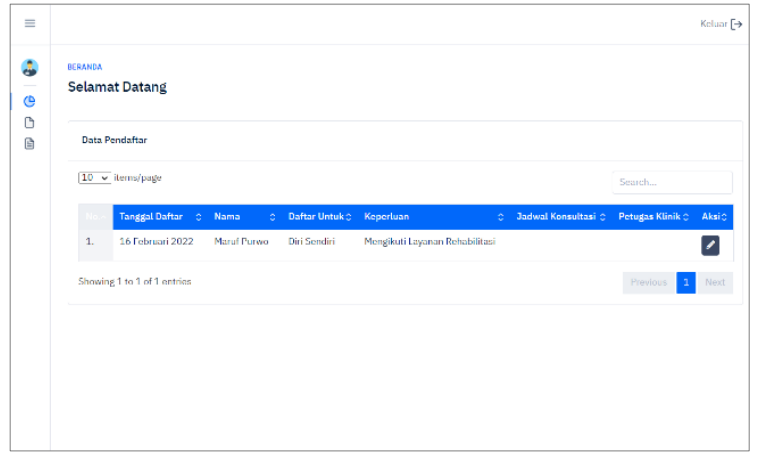

Gambar 12. Tampilan Halaman Data Pendaftar pada user Petugas Administrasi

Pada gambar 12 di atas, Petugas administrasi akan melihat data pendaftar konsultasi yang akan ditindaklanjuti dengan menenetukan jadwal pelaksanaan konsultasi dan petugas klinik yang menangani klien tersebut.

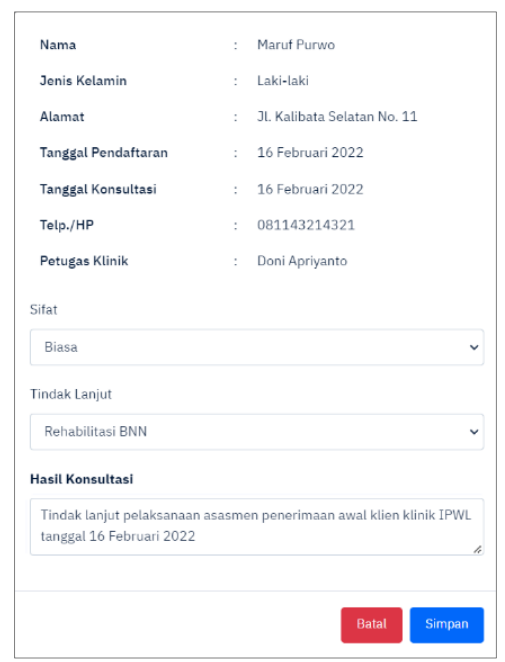

Gambar 13. Tampilan Hasil Tindak Lanjut Konsultasi Klien

Setelah pelaksanaan konsultasi, petugas klinik dapat meng-input hasil konsultasi tersebut sebagai bentuk tindaklanjut seperti yang terlihat pada gambar 13.

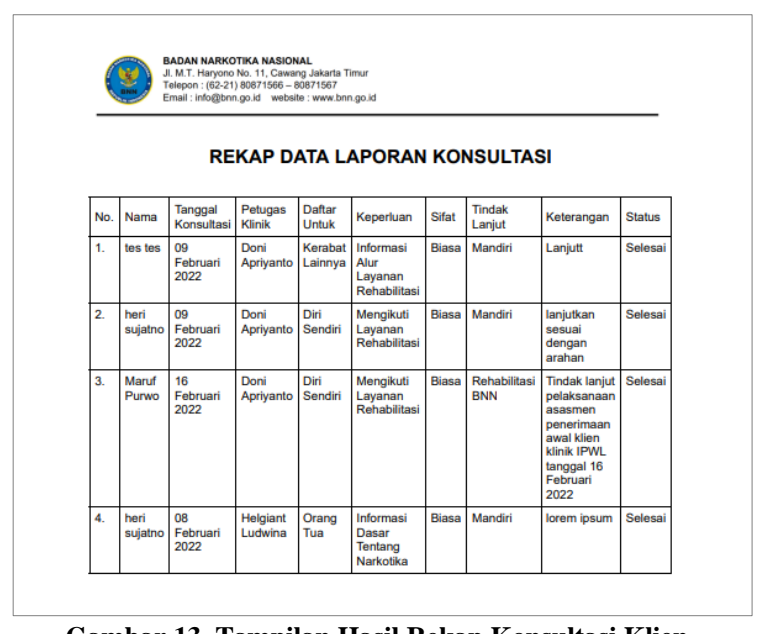

Gambar 13. Tampilan Hasil Rekap Konsultasi Klien
Pada halaman petugas administrasi, rekap hasil pelaksanaan konsultasi klien yang telah berjalan dapat dilihat pada gambar 13, petugas administrasi dapat mencari data klien yang telah melakukan konsultasi beserta hasil dari tindaklanjut pelaksanaan konsultasi tersebut. Selain itu rekap hasil pelaksanaan konsultasi tersebut dapat disajikan sebagai bentuk laporan kepada Kepala Satuan Kerja Kedeputian Bidang Rehabilitasi BNN.

\section{KESIMPULAN DAN SARAN}

Melalui sistem informasi pendaftaran konsultasi klien, calon klien tidak harus datang langsung untuk melakukan pendaftaran sehingga lebih efisien dalam segi waktu dan biaya. Memudahkan admin untuk mengolah data klien pendaftar konsultasi dan mempercepat proses verifikasi pendaftaran. Selain itu dengan proses pendaftaran yang dilakukan secara online maka diharapkan dalam mengurangi anggaran belanja persediaan pengadaan kertas formulir pendaftaran. Dengan adanya sistem ini pembuatan laporan menjadi lebih cepat dan data yang dihasilkan lebih akurat.

Saran untuk sistem informasi yang telah dirancang dapat dikembangkan menjadi sistem informasi asasmen dan konseling rawat jalan, yang lebih komplek dimana sistem tersebut nantinya tidak hanya memproses pendaftaran konsultasi klien saja, tetapi juga menyediakan informasi grafis seperti data penyalahguna meliputi rentang usia, pendidikan, jenis kelamin dan data lainnya, serta data jenis penggunaan NAPZA. Sistem informasi yang sudah dirancang selanjutnya bisa dikembangkan lagi dengan menambah fitur-fitur yang menarik seperti live chat, dan menambah konten-konten yang dapat di-update secara berkala oleh admin.

\section{DAFTAR PUSTAKA}

[1] A. A. Hasibuan, "Narkoba dan Penanggulangannya," J. Ilm. Bid. Pendidik., vol. 11, no. 1, pp. 33-44, 2017.

[2] V. Sofica, S. T. Agista, R. Ningasih, and M. Septiani, "Aplikasi Pendaftaran Pasien Rawat Jalan Online pada Klinik Mulya Medika menggunakan Waterfall," Bianglala Inform., vol. 7, no. 1, pp. 43-49, 2019.

[3] R. Sopandi, A. Taufik, A. Abdussomad, and R. Kurnia, "Rancang Bangun Sistem Informasi Pendaftaran Pasien Berbasis Web Pada Klinik Johar Kabupaten Karawang," Indones. J. Softw. Eng., vol. 5, no. 2, pp. 6170, 2019, doi: 10.31294/ijse.v5i2.6958.

[4] A. Kadir, Pengenalan Sistem Informasi Edisi Revisi. Yogyakarta: Andi, 2014.

[5] M. Shalahuddin and R. A. Sukamto, Rekayasa Perangkat Lunak: Terstruktur dan Berorientasi Objek Edisi Revisi. Bandung: Informatika, 2018.

[6] A. Andriani, Manajemen basis data: pemodelan, perancangan, dan penerapan. 
Yogyakarta: Deepublish, 2016.

[7] R. Abdulloh, 7 In 1 pemrograman web untuk pemula. Jakarta: PT. Elex Media Komputindo, 2019.

[8] M. K. Ruhul Amin, "Siswa Baru Pada Smk Budhi Warman 1 Jakarta," J. Ilmu Pengetah. dan Teknol. Komput., vol. 2, no. 2, pp. 113121, 2017.

[9] W. Erawati, "Perancangan Sistem Informasi Penjualan Dengan Pendekatan Metode Waterfall," J. Media Inform. Budidarma, vol. 3, no. 1, p. 1, 2019, doi: 10.30865/mib.v3i1.987. 